\title{
Effects of foliar application of inactivated yeast on the phenolic composition of Vitis vinifera L. cv. Agiorgitiko grapes under different irrigation levels
}

This article was published in the following Dove Press journal: International Journal of Wine Research

19 May 2017

Number of times this article has been viewed

\author{
Charikleia Kogkou' \\ Evangelia Chorti \\ Maria Kyraleou' \\ Stamatina Kallithraka' \\ Stefanos Koundouras ${ }^{3}$ \\ Gerard Logan' \\ loannis Kanakis ${ }^{4}$ \\ Yorgos Kotseridis' \\ 'Laboratory of Enology, Department \\ of Food Science and Technology, \\ Agricultural University of Athens, \\ Athens, Greece; ${ }^{2}$ Cooperative \\ Winery of Nemea, Nemea, Greece; \\ ${ }^{3}$ Laboratory of Viticulture, School of \\ Agriculture, Aristotle University of \\ Thessaloniki, Thessaloniki, Greece; \\ ${ }^{4}$ Fassoulis Grapevine Nurseries, \\ Nemea, Greece
}

\begin{abstract}
Recent climate changes have caused the rising of average growing season temperatures leading to the advancement of vine phenological stages and to earlier harvests. This could result in the production of grapes with advanced berry sugar accumulation, but incomplete phenolic ripeness, thereby jeopardizing wine quality. This study aims to evaluate the effects of the application of a new product consisting of yeast derivatives on the phenolic maturity and composition of Agiorgitiko grapes and wines, under contrasting water conditions. The experiment was arranged as a $2 \times 2$ factorial design in a commercial vineyard situated in southern Greece, combining foliar spraying with LalVigne ${ }^{\circledR}$ Mature (two applications after veraison and an untreated control) and water conditions (deficit irrigation and nonirrigated). Irrigation accelerated berry sugar accumulation, increased berry weight and anthocyanin content, and decreased skin tannin concentration. Spraying with yeast derivatives did not affect phenolic content of berry components, and it had no effect on must attributes. Foliar application of yeast derivatives resulted in a higher phenolic potential of the produced wines, only when combined with irrigation.
\end{abstract}

Keywords: foliar spray, deficit irrigation, phenolic maturity, anthocyanins, tannins

\section{Introduction}

According to the International Panel on Climate Change Report, in each of the last 3 decades the atmosphere has been warmer than in the preceding one. ${ }^{1}$ Jones et al reported that in a 49-year period (1950-1999), growing season average temperatures have increased in the world's high-quality wine producing regions by $1.26^{\circ} \mathrm{C}$, and predict that temperatures will increase within the $2000-2049$ period by an average of $0.42^{\circ} \mathrm{C}$ per decade and $2.04^{\circ} \mathrm{C}$ overall. ${ }^{2}$ Global warming could push warm vine growing regions, such as Greece, pass the point where they can produce balanced and suitable fruit for winemaking, at least for certain varieties. ${ }^{3}$ Studies have shown that climate change causes an advancement in grapevine phenology with a shortened time between stages and an earlier harvest date. ${ }^{4-6}$ In the recent decades, harvests tend to occur sooner, berry sugar content tends to be higher ${ }^{6}$ with a consequent higher alcohol content of the produced wine, whereas phenolic and aromatic maturity are not always achieved. ${ }^{7}$ Lack of optimal phenolic maturity of grapes can lead to the production of wines with astringent tannins ${ }^{2}$ and have negative effects on wine color, flavor, texture, and overall quality. ${ }^{7}$

Irrigation is a common viticultural practice aiming to optimize vine performance under semiarid conditions, most importantly in regions like Greece, where temperature and precipitation patterns are predicted to change, increasing the frequency of drought
Correspondence: Evangelia Chorti Cooperative Winery of Nemea, 130 Papaconstantinou Avenue, Nemea, 20500, Greece

Tel +302746022210 Ext 18

Fax +302746023052

Email echorti@nemeanwines.gr 
incidents. ${ }^{2}$ In Nemea area, situated in Southern Greece, water shortage is the main environmental constraint for wine grape growing, ${ }^{8}$ as grapevines are often exposed to high water deficit during summer and most of the vineyards are dryfarmed, as irrigation of grapevines is still prohibited in Greek Protected Designation of Origin wine producing areas. Interestingly, moderate water deficit is reported to positively affect grape flavonoid biosynthesis, increasing the concentration of anthocyanins ${ }^{9,10}$ and particularly malvidin levels. ${ }^{11}$ Basile et al suggested that the concentration of anthocyanins and polyphenols was increased in Cabernet Sauvignon when the vines experienced a mild water deficit between fruit set and veraison, and a moderate-to-severe water deficit during the post-veraison period. ${ }^{12}$ However, under semiarid conditions, highly water-stressed vines can also produce poor quality grapes with lower color and phenolic content. ${ }^{13}$

A new foliar spray with the commercial name LalVigne ${ }^{\circledR}$ Mature (Lallemand Inc., ON, Canada) was developed recently, consisting of $100 \%$ natural, inactivated wine yeast (Saccharomyces cerevisiae) derivatives with the aim to improve phenolic compound maturity in grapes. The expected changes in the phenolic content of treated berries could also be explained by a vine-pathogen interaction, as yeasts are recognized as pathogens and activate plant defense mechanisms, ${ }^{14}$ thereby enhancing secondary metabolism in the ripening fruit. ${ }^{15}$

Vitis vinifera L. cv. Agiorgitiko is a red grape variety cultivated in the Nemea region of Greece, where it is used to produce Denomination of Origin wines, and it is the most widely cultivated indigenous variety for production of red wines in Greece. The aim of this research was to evaluate the combined effect of foliar application of LalVigne ${ }^{\circledR}$ Mature and irrigation on the phenolic maturity of Agiorgitiko grapes. The outcomes of such research would be of practical interest to winegrowers and winemakers alike for better management of the phenolic maturation of Agiorgitiko grapes, and optimization of the sensory attributes of the produced wines.

\section{Materials and methods Experimental conditions}

The experiment was conducted in 2013 in a 10-year-old commercial vineyard in Leontio sub-region of Nemea (NorthEastern Peloponnese, Greece), at an altitude of $300 \mathrm{~m}$ above sea level. Vineyard soil texture (w/w) was $30 \%$ sand, $25 \%$ silt, and $45 \%$ clay. The vineyard was planted with $V$. vinifera L. cv. Agiorgitiko grafted onto 1103 Paulsen rootstock. Vine spacing was $1 \mathrm{~m}$ and row spacing was $2.5 \mathrm{~m}$, and the vines were trained to a bilateral cordon consisting of four spurs per cordon, pruned to two buds.
A trial site of three blocks was established, each block consisting of three buffer and two treatment rows. In each block, foliar sprays with LalVigne ${ }^{\circledR}$ Mature and deficit irrigation were applied according to a factorial experimental design, thus producing four treatments: control $(C$, nonirrigated, non-sprayed), deficit irrigated (IR, non-sprayed), foliar sprayed (SP) LalVigne ${ }^{\circledR}$ Mature (nonirrigated), and combined deficit irrigated and foliar sprayed (IR/SP). The application of LalVigne ${ }^{\circledR}$ Mature consisted of two foliar sprayings on the whole canopy, with a dosage of $1 \mathrm{~kg} / \mathrm{ha}$ of the product diluted in water, one on July 27, 2013 (70\% of veraison) and one on August 1, 2013. Irrigation was applied by a drip irrigation system with two applications on same dates with a total of $70 \mathrm{~mm}$ of water. Canopy management was the same for all treatments and included shoot tucking and positioning, and shoot topping to $1.2 \mathrm{~m}$ above the bottom wire. Harvesting was conducted simultaneously for the four treatments on September 15, 2013. On the same day, 750 berries were sampled from each replicate of each treatment.

\section{Phenolic content of grapes}

In must several analytical parameters (sugar content expressed in Baumé degrees $\left({ }^{\circ} \mathrm{Be}\right), \mathrm{pH}$, titratable, acidity) were determined in accordance with the Compendium of International Methods of Analysis of Wines and Musts. ${ }^{16}$ Fifty berries from each treatment were homogenized using Ultra Turrax T25 at $20,000 \mathrm{rpm}$ for $1 \mathrm{~min}$. Total phenolic compounds and anthocyanin content were measured according to Iland et al; $1 \mathrm{~g}$ of the homogenate (in triplicate) was transferred into a centrifuge tube. An amount of $10 \mathrm{~mL} 50 \% \mathrm{v} / \mathrm{v}$ aqueous ethanol at $\mathrm{pH}$ 2 , was then added and mixed for $1 \mathrm{~h}$. After centrifugation at 4,000 rpm for $10 \mathrm{~min}, 0.5 \mathrm{~mL}$ of the supernatant was added to $10 \mathrm{~mL} 1 \mathrm{M} \mathrm{HC} 1$ and mixed thoroughly. After $3 \mathrm{~h}$, absorbance at 700,520 , and $280 \mathrm{~nm}$ was recorded. ${ }^{17}$

Anthocyanin content, extractable anthocyanins, and percentage contribution of extractable seed tannins to total berry tannins (seed \%) were determined as described by Ribéreau-Gayon et al, slightly modified. An amount of $20 \mathrm{~g}$ of the homogenate was macerated for $4 \mathrm{~h}$ with two buffers of different $\mathrm{pH}$. The $\mathrm{pH}$ of the first buffer was 1 while the $\mathrm{pH}$ of the second was 3.6. After $4 \mathrm{~h}$, the macerated samples were centrifuged (4,000 rpm, $10 \mathrm{~min}$ ) and then the anthocyanin and total phenolic content of the supernatant were measured. ${ }^{18}$

Seeds and skins of 150 berries were removed by hand from the grapes. Then, they were freeze-dried and finally ground to obtain fine powder. The extraction of skin and seed tannins was carried out according to previously reported methods. ${ }^{19}$ An amount of $3 \mathrm{~g}$ of the lyophilized powder was 
first extracted with $25 \mathrm{~mL}$ of acetone/water (80:20, v/v) for $3 \mathrm{~h}$ and then with $25 \mathrm{~mL}$ of methanol/water $(60: 40, \mathrm{v} / \mathrm{v})$ for $2.5 \mathrm{~h}$. The centrifuged supernatants were combined and evaporated under reduced pressure at $30^{\circ} \mathrm{C}$ to remove organic solvents; the residue was dissolved in water and lyophilized to obtain a crude tannin extract.

Parts of the crude extracts were re-dissolved in a model solution (12\% ethanol; $5 \mathrm{~g} / \mathrm{L}$ tartaric acid; $\mathrm{pH} 3.5$ adjusted with $1 \mathrm{~N} \mathrm{NaOH}$ ) for the determination of total phenol content by Folin-Ciocalteu method, ${ }^{20}$ antioxidant activity ${ }^{21}$ and total tannin estimation was performed with the protein precipitation assay using bovine serum albumin. ${ }^{22}$ Absorbance measurements were recorded on a Jasco V-530 UV/VIS spectrophotometer (Jasco Inc, Easton, MD, USA).

Anthocyanins were extracted with acidified methanol $(0.1 \%$ $\mathrm{HCl} 12 \mathrm{~N}$ ) from $1 \mathrm{~g}$ of dried skin powder three successive times (for 4, 18, and $24 \mathrm{~h}$ ). After centrifugation, the supernatants were combined and analyzed for total anthocyanins. ${ }^{18}$ Highperformance liquid chromatography (HPLC) analysis was carried out for the determination of monomeric anthocyanins on a Restek pinnacle II C18 (Restek Corporation, Bellefonte, PA, USA), $250 \times 4.6,5 \mu \mathrm{m}$ at a flow rate of $1 \mathrm{~mL} / \mathrm{min}$, with a $10 \mu \mathrm{L}$ injection volume, detection at $520 \mathrm{~nm}$, and the following solvent program: $90 \%$ eluent A for $1 \mathrm{~min}$, then from $90 \%$ to $50 \%$ in $22 \mathrm{~min}$, from $50 \%$ to $5 \%$ in $10 \mathrm{~min}$, which was kept isocratic for a further $2 \mathrm{~min}$. Eluent $\mathrm{A}$ was $10 \%$ aqueous formic acid and eluent $B$ methanol. Identification and quantification of anthocyanins was performed by establishing a calibration curve for malvidin-3-O-glucoside (Mv) as described in Kallithraka et al. ${ }^{23}$ Results were expressed as $\mu \mathrm{g}$ Mv per $\mathrm{g}$ dry skin weight $(\mathrm{SkW})$. All analyses were performed in triplicate.

\section{Microvinification}

Triplicate fermentations were performed for each treatment, one for each field replicate. After crushing and destemming, $40 \mathrm{mg} / \mathrm{L} \mathrm{SO}_{2}$ (as potassium metabisulfite) and $3 \mathrm{~g} / \mathrm{hL} \mathrm{Safizym}$ Colour (Fermentis, Marcq-en-Baroeul, France) were added to the grapes. Lyophilized yeasts of the commercial strain UCLM S377 (S. cerevisiae; Fermentis) at $20 \mathrm{~g} / \mathrm{hL}$, previously hydrated in water $\left(15 \mathrm{~min}, 38^{\circ} \mathrm{C}\right)$ and yeast nutrients Bioferm ${ }^{\circledR}$ Xtrem (Fermentis) at $20 \mathrm{~g} / \mathrm{hL}$ were also added. Beginning on the second day of fermentation, and for the following days, two punch down timings per day were conducted.

After 7 days of maceration at controlled temperature $\left(23^{\circ} \mathrm{C}-25^{\circ} \mathrm{C}\right)$, the wines were pressed and transferred to other tanks for malolactic fermentation after inoculating with Viniflora $^{\circledR}$ Oenos $^{\mathrm{TM}}$ (Oenococcus oeni; Chr. Hansen, Hørsholm, Denmark) bacteria. Malolactic fermentation was completed at room temperature after 1 week. The wines were racked, supplemented with $50 \mathrm{mg} / \mathrm{L} \mathrm{SO}_{2}$ (as potassium metabisulfite), filtered, bottled, and stored at $15 \pm 2^{\circ} \mathrm{C}$ in the dark until analyzed.

\section{Analytical wine parameters}

In wines, several analytical parameters (alcohol content, $\mathrm{pH}$, titratable, acidity, hue, color intensity, total polyphenol index - OD280) were determined after bottling according to the Compendium of International Methods of Analysis of Wines and Musts. ${ }^{16}$ In addition, total phenolic content by Folin-Ciocalteau method, ${ }^{20}$ total anthocyanin content, ionization index, total tannins, ${ }^{18,22}$ antioxidant activity, ${ }^{21}$ and monomeric anthocyanins by $\mathrm{HPLC}^{23}$ were also determined. All analyses were performed in triplicate.

\section{Statistical analysis}

A two-factor analysis of variance (ANOVA) was used to test the main effects and interactions of yeast application and irrigation on grape and wine composition, using SPSS software (version 20.0; IBM Corporation, Armonk, NY, USA). One-way ANOVA was also conducted to explore differences among individual treatments. Comparison of means was performed using Duncan's multiple range test at $p \leq 0.05$.

\section{Results \\ Grape growth and must composition components}

Foliar application of yeast derivatives alone had no effect on berry (BW) and seed (SeW) weight, neither on sugar content $\left({ }^{\circ} \mathrm{Be}\right)$, titratable acidity (TA) nor $\mathrm{pH}$ (Figure 1$)$. Yeast application only affected $\mathrm{SkW}$, with higher values for $\mathrm{C}$ vines as compared to sprayed ones (Table 1). BW and SkW were strongly affected by water status, increasing means with irrigation; however, irrigation did not affect SeW (Table 1). BW was increased by $16.3 \%$ and $15.3 \%$ in IR and in IR/SP respectively $(p \leq 0.05)$ compared to $\mathrm{C}$, and a similar trend was observed for SkW values (Figure 1). Concerning juice composition, grapes of irrigated vines presented higher ${ }^{\circ} \mathrm{Be}$ and lower TA in the must than nonirrigated ones (Table 1), but $\mathrm{pH}$ was not affected by irrigation (Table 1 and Figure 1).

\section{Phenolic content of grapes}

In pooled data of irrigation and yeast applications (Table 2), total anthocyanin and total phenol levels were affected by both irrigation and yeast treatment, but only when results were expressed on a per berry basis, with higher levels for 
irrigated and non-sprayed grapes, respectively. Among the four treatments (Figure 2), SP grapes had the lowest total anthocyanin and total phenol content per berry (anthocyanin content per berry was reduced by $\sim 30 \%$ and total phenol content per berry by $35 \%$ in SP as compared to C).
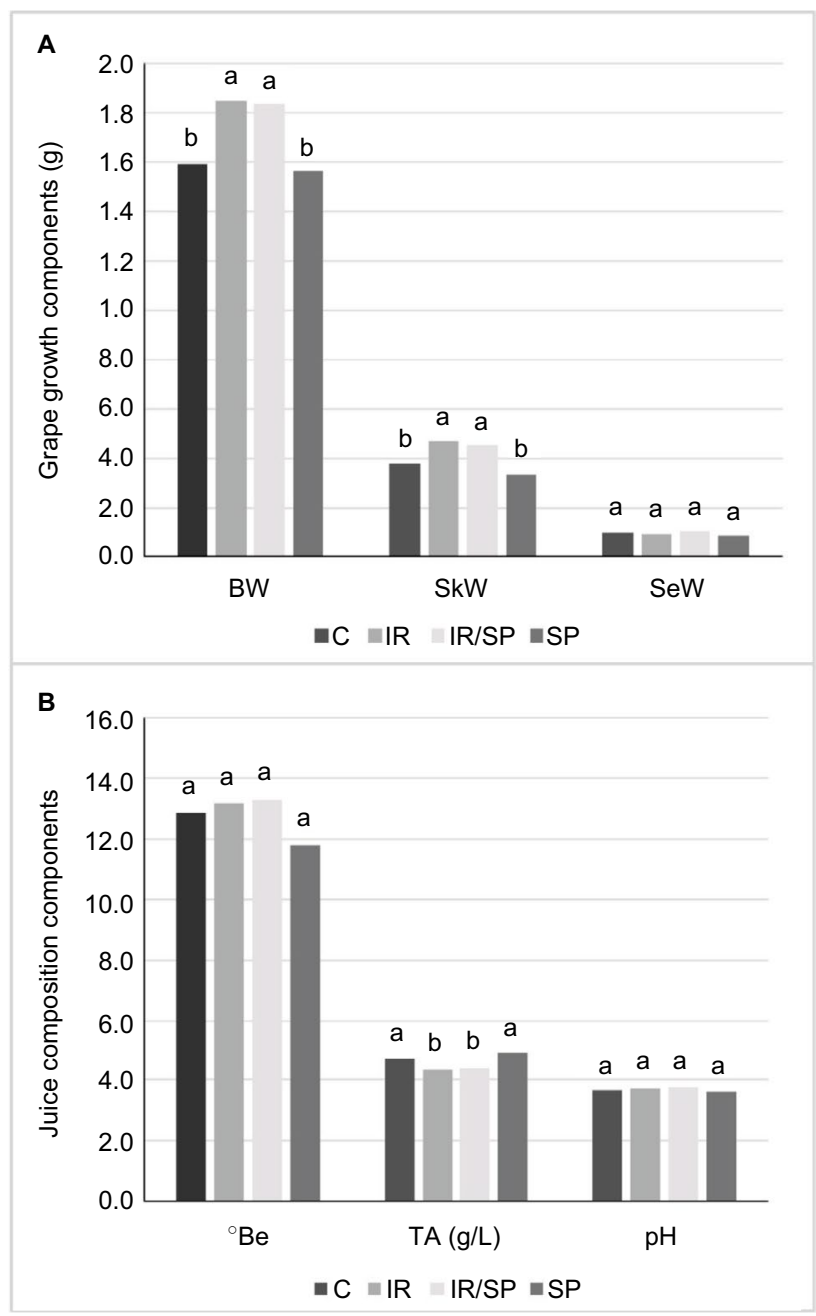

Figure I Grape growth (A) and juice composition (B) components at harvest. Notes: Different letters within a parameter denote significant differences (Duncan's test $p \leq 0.05$ ).

Abbreviations: BW, berry weight; C, control; IR, deficit irrigated; IR/SP, combined deficit irrigated and foliar sprayed; SP, foliar sprayed; SkW, skin weight; SeW, seed weight; ${ }^{\circ} \mathrm{Be}$, Baumé degrees; TA, titratable acidity.
A significant irrigation $\times$ yeast application interaction was also observed for total phenols (in absorbance units (au)/ berry); when irrigation regimes where analyzed separately, differences between yeast treatments were observed only for nonirrigated vines (2.31 au/berry for non-sprayed as compared to $1.50 \mathrm{au} /$ berry for sprayed vines) while no differences were observed between yeast treatments for the irrigated vines (2.40 and $2.35 \mathrm{au} /$ berry, respectively).

Concerning individual anthocyanins (Dp, delphinidin-3-Oglucoside; $\mathrm{Cn}$, cyanidin-3-O-glucoside; Pt, petunidin-3-Oglucoside; Pn, peonidin-3-O-glucoside; Mv, MvAc, malvidin 3-O-acetate-glucoside; $\mathrm{MvCm}$, malvidin 3-O-coumarateglucoside), there were few differences among treatments in the levels of monomeric anthocyanins and their esters in berry skins (Figure 3). Pt production was enhanced both by deficit irrigation and yeast application $(0.07 \mathrm{mg} / \mathrm{g}$ of skins for IR, IR/ SP, and SP compared to $0.05 \mathrm{mg} / \mathrm{g}$ of skins for C), while Pn was higher in SP $(0.07 \mathrm{mg} / \mathrm{g}$ of skins). As shown in Table 3, neither irrigation nor yeast application showed any significant impact on individual anthocyanin concentrations in berry skins, with the exception of $\mathrm{Dp}$ between yeast applications.

Irrigation and yeast application did not exert any significant effect on skin and seed phenolic composition (Table 4), with the exception of skin tannins in mg catechin/skin $\mathrm{g}$ between irrigation regimes (higher levels in nonirrigated vines). The antioxidant activity of skins and seeds did not differ among different treatments (Table 4 and Figure 4). There was also no interaction between irrigation and yeast application for any of the measured parameters (Table 4).

\section{Wine composition}

Similar to grape juice composition, the foliar application of yeast derivatives did not affect any of the wine parameters measured (Table 5); in contrast, irrigation increased wine alcohol concentration, $\mathrm{pH}$, and color hue, and decreased the TA, which is in agreement with the higher sugar content and the lower acidity of the grapes of irrigated vines (Table 1 and Figure 1). There was no significant yeast $\times$ irrigation interaction for any

Table I Irrigation (I) and yeast application (Y) effects on grape growth components measured at harvest

\begin{tabular}{llllllll}
\hline Factors & Treatments & BW & SkW & SeW & ${ }^{\circ} \mathbf{B e}$ & TA & pH \\
\hline $\mathrm{I}$ & Nonirrigated & $1.57^{\mathrm{b}}$ & $0.355^{\mathrm{b}}$ & 0.089 & $12.3^{\mathrm{b}}$ & $4.92^{\mathrm{a}}$ & 3.63 \\
& Irrigated & $1.84^{\mathrm{a}}$ & $0.462^{\mathrm{a}}$ & 0.096 & $13.3^{\mathrm{a}}$ & $4.40^{\mathrm{b}}$ & 3.73 \\
$\mathrm{Y}$ & Non-sprayed & 1.72 & $0.425^{\mathrm{a}}$ & 0.093 & 13.0 & 4.56 & 3.70 \\
& Sprayed & 1.69 & $0.392^{\mathrm{b}}$ & 0.093 & 12.5 & 4.76 & 3.66 \\
$\mathrm{I} \times \mathrm{Y}$ & & $\mathrm{ns}$ & $\mathrm{ns}$ & $\mathrm{ns}$ & $*$ & $\mathrm{~ns}$ & $\mathrm{~ns}$ \\
\hline
\end{tabular}

Notes: Statistically significant differences within a factor are indicated by different letters $(p \leq 0.05)$; *represents significance of the irrigation $\times$ yeast application $($ I $\times Y)$ interaction at $p \leq 0.05$.

Abbreviations: ns, not significant; BW, berry weight; SkW, skin weight; SeW, seed weight; ${ }^{\circ} \mathrm{Be}$, Baumé degrees; TA, titratable acidity. 
Table 2 Irrigation (I) and yeast application (Y) effects on phenolic potential of grapes

\begin{tabular}{llllll}
\hline Factors & Treatments & $\begin{array}{l}\text { Anthocyanins } \\
\text { (mg/berry) }\end{array}$ & $\begin{array}{l}\text { Anthocyanins } \\
\text { (mg/berry g) }\end{array}$ & $\begin{array}{l}\text { Total phenols } \\
\text { (au/berry) }\end{array}$ & $\begin{array}{l}\text { Total phenols } \\
\text { (au/berry g) }\end{array}$ \\
\hline $\mathrm{I}$ & Nonirrigated & $1.25^{\mathrm{b}}$ & 0.83 & $1.87^{\mathrm{b}}$ & 1.25 \\
$\mathrm{Y}$ & Irrigated & $1.63^{\mathrm{a}}$ & 0.88 & $2.38^{\mathrm{a}}$ & 1.28 \\
& Non-sprayed & $1.63^{\mathrm{a}}$ & 0.91 & $2.36^{\mathrm{a}}$ & 1.32 \\
$\mathrm{IXY}$ & Sprayed & $1.25^{\mathrm{b}}$ & 0.80 & $1.89^{\mathrm{b}}$ & 1.20 \\
\hline
\end{tabular}

Notes: Statistically significant differences within a factor are indicated by different letters $(p \leq 0.05)$; ****epresents significance of the irrigation $\times$ yeast application $(I \times Y)$ interaction at $p \leq 0.001$.

Abbreviations: ns, not significant; au, absorbance units.

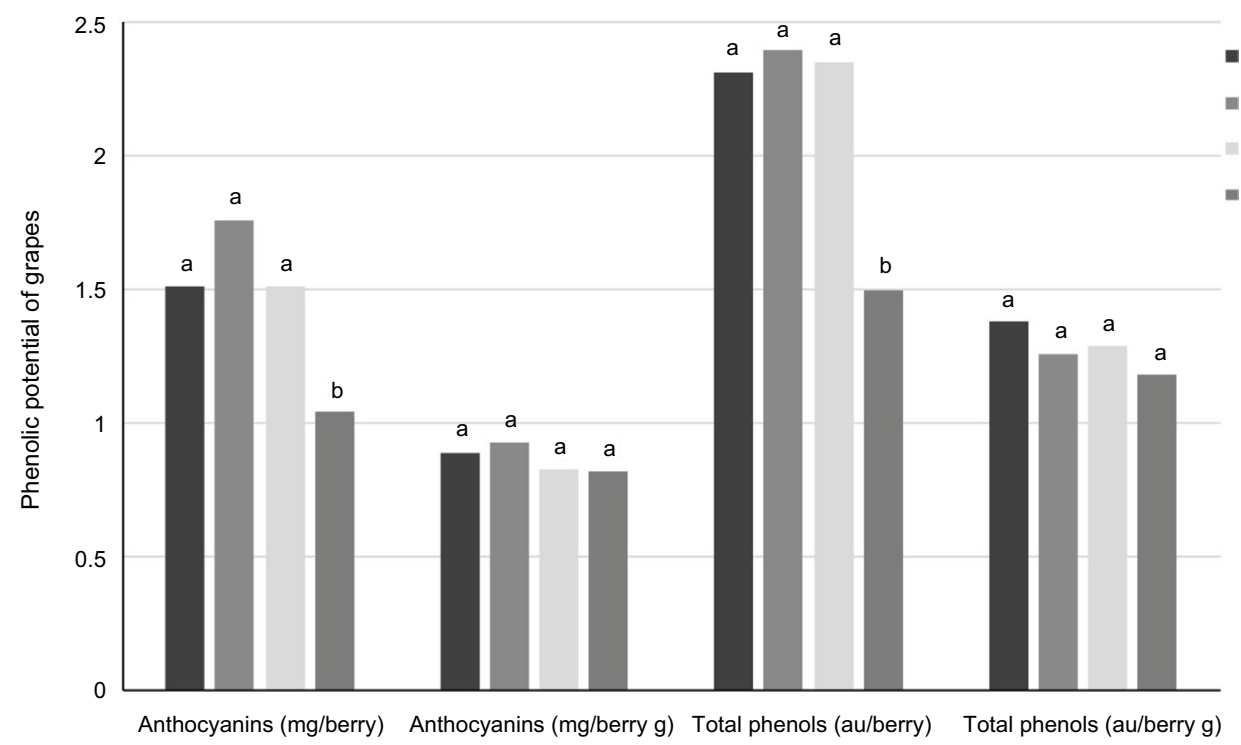

Figure 2 Phenolic potential of grapes at harvest.

Notes: Different letters within a parameter denote significant differences (Duncan's test $p \leq 0.05$ ).

Abbreviations: au, absorbance units; C, control; IR, deficit irrigated; IR/SP, combined deficit irrigated and foliar sprayed; SP, foliar sprayed.

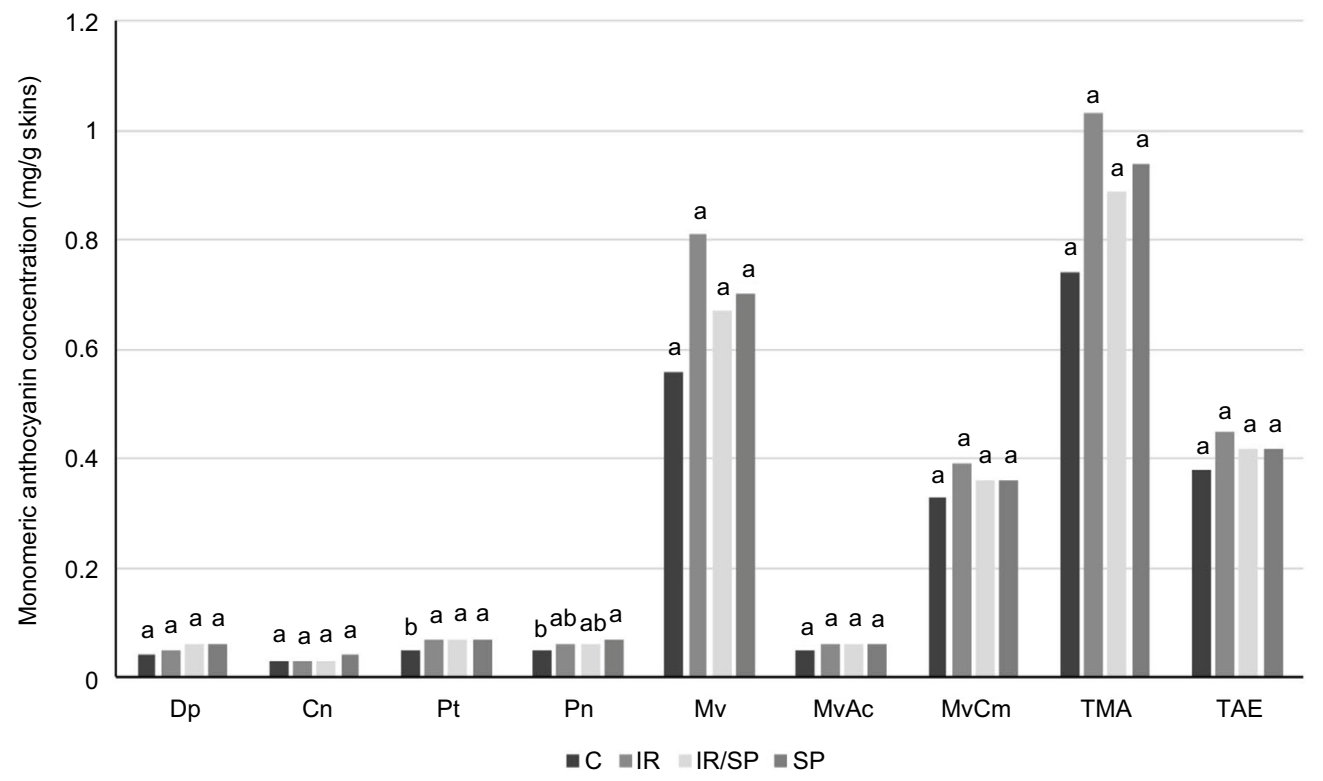

Figure 3 Anthocyanin concentration (mg/g skin fresh weight) of Agiorgitiko grape skin at ripeness stage.

Notes: Different letters within a parameter denote significant differences (Duncan's test $p \leq 0.05$ ).

Abbreviations: Dp, delphinidin-3-O-glucoside; Cn, cyanidin-3-O-glucoside; Pt, petunidin-3-O-glucoside; Pn, peonidin-3-O-glucoside; Mv, malvidin-3-O-glucoside; MvAc, malvidin 3-O-acetate-glucoside; MvCm, malvidin 3-O-coumarate-glucoside; TMA, total monomeric anthocyanins in mg of malvidin-3-O-glucoside/g of skins; TAE, total anthocyanin esters in $\mathrm{mg}$ of malvidin-3-O-glucoside/g of skins; C, control; IR, deficit irrigated; IR/SP, combined deficit irrigated and foliar sprayed; SP, foliar sprayed. 
Table 3 Irrigation (I) and yeast application (Y) effects on anthocyanin concentration ( $\mathrm{mg} / \mathrm{g}$ skin fresh weight) of Agiorgitiko grape skin at ripeness stage

\begin{tabular}{lllllllllll}
\hline Factors & Treatments & Dp & Cn & Pt & Pn & Mv & MvAc & MvCm & TMA & TAE \\
\hline I & Nonirrigated & 0.050 & 0.035 & 0.060 & 0.062 & 0.631 & 0.059 & 0.344 & 0.838 & 0.403 \\
& Irrigated & 0.057 & 0.034 & 0.068 & 0.064 & 0.736 & 0.061 & 0.377 & 0.959 & 0.438 \\
Y & Non-sprayed & $0.049^{\mathrm{b}}$ & 0.034 & 0.061 & 0.057 & 0.684 & 0.059 & 0.361 & 0.884 & 0.420 \\
& Sprayed & $0.058^{\mathrm{a}}$ & 0.036 & 0.067 & 0.069 & 0.683 & 0.062 & 0.360 & 0.913 & 0.421 \\
& & $\mathrm{~ns}$ & $\mathrm{~ns}$ & $\mathrm{~ns}$ & $\mathrm{~ns}$ & $\mathrm{~ns}$ & $\mathrm{~ns}$ & $\mathrm{~ns}$ & $\mathrm{~ns}$ & $\mathrm{~ns}$ \\
\hline
\end{tabular}

Note: Statistically significant differences within a factor are indicated by different letters $(p \leq 0.05)$.

Abbreviations: ns, not significant; $\mathrm{Dp}$, delphinidin-3-O-glucoside; $\mathrm{Cn}$, cyanidin-3-O-glucoside; Pt, petunidin-3-O-glucoside; Pn, peonidin-3-O-glucoside; Mv, malvidin-3-Oglucoside; MvAc, malvidin 3-O-acetate-glucoside; MvCm, malvidin 3-O-coumarate-glucoside; TMA, total monomeric anthocyanins in mg of malvidin-3-O-glucoside/g of skins; TAE, total anthocyanin esters in $\mathrm{mg}$ of malvidin-3-O-glucoside/g of skins.

Table 4 Irrigation (I) and yeast application (Y) effects on phenolic composition of Agiorgitiko grape skin and seeds at harvest

\begin{tabular}{|c|c|c|c|c|c|c|c|}
\hline \multirow{2}{*}{ Factors } & \multirow{2}{*}{ Treatments } & \multicolumn{3}{|l|}{ Skin } & \multicolumn{3}{|c|}{ Seeds } \\
\hline & & SkC & TSkP & SkAA & $\mathrm{SeC}$ & TSeP & SeAA \\
\hline \multirow[t]{2}{*}{ I } & Nonirrigated & $2.21^{\mathrm{a}}$ & 11.91 & 0.04 & 16.27 & 53.08 & 0.13 \\
\hline & Irrigated & $1.55^{\mathrm{b}}$ & 11.04 & 0.04 & 17.64 & 54.75 & 0.15 \\
\hline \multirow[t]{2}{*}{ Y } & Non-sprayed & 1.86 & 11.98 & 0.04 & 18.90 & 57.26 & 0.16 \\
\hline & Sprayed & 1.90 & 10.98 & 0.04 & 15.01 & 50.57 & 0.13 \\
\hline$I \times Y$ & & ns & ns & ns & ns & ns & ns \\
\hline
\end{tabular}

Note: Statistically significant differences within a factor are indicated by different letters $(p \leq 0.05)$.

Abbreviations: ns, not significant; SkC, skin tannins in mg catechin/skin g; SeC, seed tannins in mg catechin/seed g; TSkP, total skin phenols in g of gallic acid/skin g; TSeP, total seed phenols in $\mathrm{g}$ of gallic acid/skin g; SkAA, skin antioxidant activity in mM trolox/skin g; SeAA, seed antioxidant activity in mM trolox/skin g.

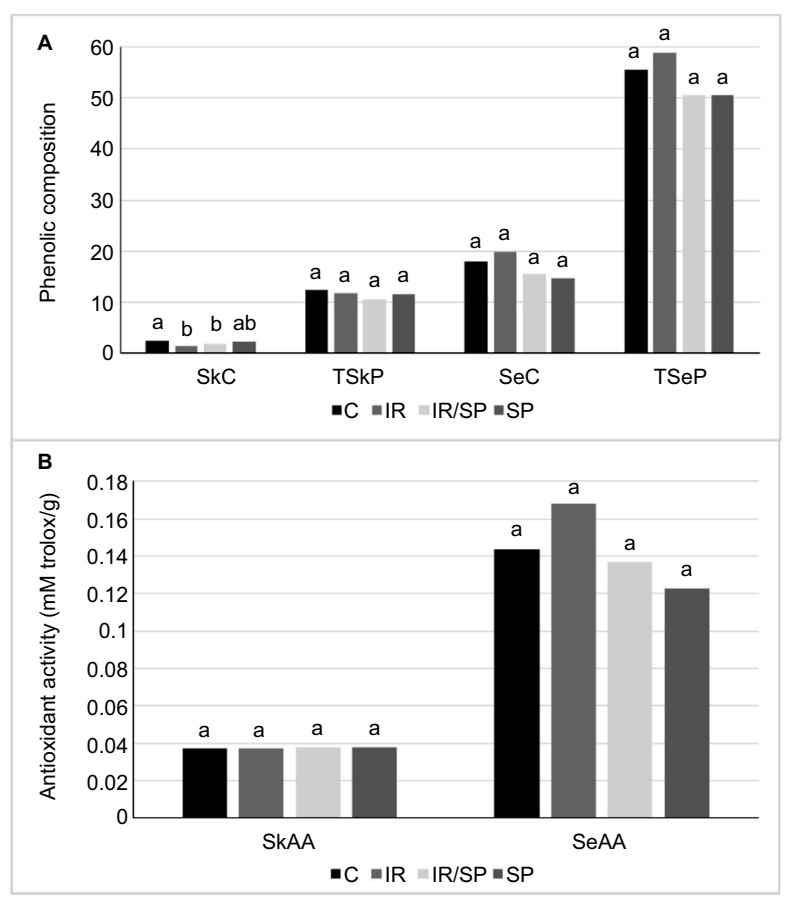

Figure 4 Phenolic composition of Agiorgitiko grape skin and seed at harvest: skin and seed tannins and phenols (A) and skin and seed antioxidant activity (B).

Notes: Different letters within a parameter denote significant differences (Duncan's test $p \leq 0.05)$.

Abbreviations: SkC, skin tannins in $\mathrm{mg}$ catechin/skin g; TSkP, total skin phenols in $\mathrm{g}$ of gallic acid/skin g; $\mathrm{SeC}$, seed tannins in $\mathrm{mg}$ catechin/seed g; TSeP, total seed phenols in $g$ of gallic acid/skin g; SkAA, skin antioxidant activity in mM trolox/skin g; SeAA, seed antioxidant activity in $\mathrm{mM}$ trolox/skin g; C, control; IR, deficit irrigated; IR/SP, combined deficit irrigated and foliar sprayed; SP, foliar sprayed.
Table 5 Irrigation (I) and yeast application (Y) effects on alcohol content, TA, pH, and color properties of the produced wines

\begin{tabular}{lllllll}
\hline Factors & Treatments & $\begin{array}{l}\text { Alcohol } \\
(\% \mathrm{v} / \mathbf{v})\end{array}$ & $\begin{array}{l}\text { TA } \\
(\mathbf{g} / \mathbf{L})\end{array}$ & $\mathbf{p H}$ & $\begin{array}{l}\text { Color } \\
\text { intensity }\end{array}$ & $\begin{array}{l}\text { Color } \\
\text { hue }\end{array}$ \\
\hline $\mathrm{I}$ & Nonirrigated & $12.2^{\mathrm{b}}$ & $5.4^{\mathrm{a}}$ & $3.63^{\mathrm{b}}$ & 8.46 & $0.66^{\mathrm{b}}$ \\
& Irrigated & $13.5^{\mathrm{a}}$ & $4.9^{\mathrm{b}}$ & $3.73^{\mathrm{a}}$ & 8.50 & $0.73^{\mathrm{a}}$ \\
$\mathrm{Y}$ & Non-sprayed & 12.9 & 5.1 & 3.68 & 8.63 & 0.70 \\
& Sprayed & 12.9 & 5.2 & 3.68 & 8.32 & 0.69 \\
$\mathrm{I} \times \mathrm{Y}$ & & $\mathrm{ns}$ & $\mathrm{ns}$ & $\mathrm{ns}$ & $\mathrm{ns}$ & $\mathrm{ns}$ \\
\hline
\end{tabular}

Note: Statistically significant differences within a factor are indicated by different letters $(p \leq 0.05)$

Abbreviations: $\mathrm{ns}$, not significant; TA, titratable acidity.

of the wine composition parameters; however, when combined, deficit irrigation and yeast application seemed to result in the production of wines with higher alcohol concentration (13.8 for IR/SP) and higher $\mathrm{pH}$ (Figure 5). There was no effect of either yeast application or irrigation on wine color intensity.

There were no significant factor effects and interactions for the concentration of the individual anthocyanins in the produced wines (Table 6), in accordance with their respective results in grape skins. However, when treatments were considered separately (Figure 6), the combined deficit irrigation and yeast application treatment seemed to result in the production of wines with higher levels of $\mathrm{MvCm}$, leading to higher total monomeric anthocyanin content. On the contrary, when applied without irrigation (SP), yeast foliar spray showed the lowest anthocyanin concentration of wine among the four treatments (Figure 6). 


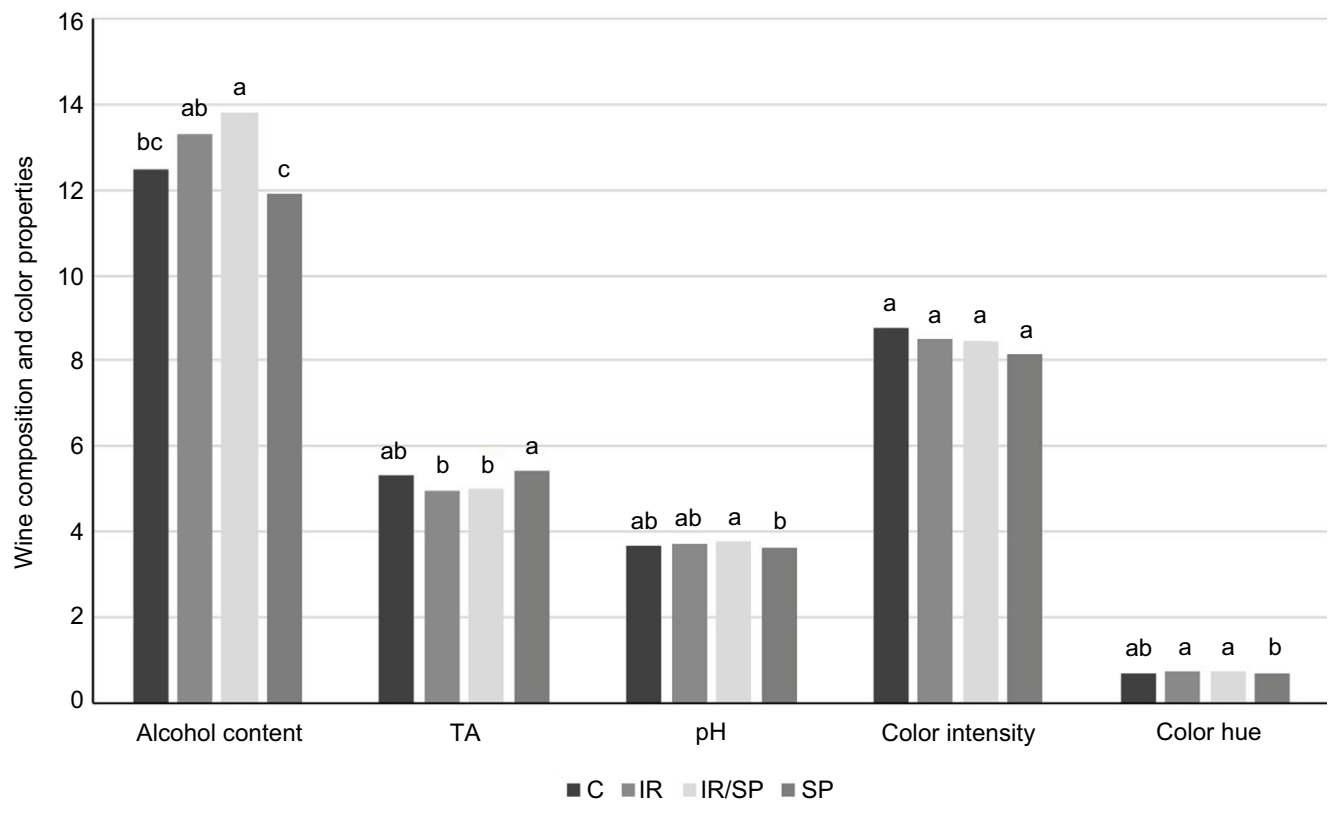

Figure 5 Alcohol content $(\% \mathrm{v} / \mathrm{v}), \mathrm{TA}(\mathrm{g} / \mathrm{L}), \mathrm{pH}$, and color properties of the produced wines.

Notes: Different letters within a parameter denote significant differences (Duncan's test $p \leq 0.05$ ).

Abbreviations: TA, titratable acidity; C, control; IR, deficit irrigated; IR/SP, combined deficit irrigated and foliar sprayed; SP, foliar sprayed.

Table 6 Irrigation $(I)$ and yeast application $(Y)$ effects on anthocyanin concentration of the produced wines

\begin{tabular}{lllllllllll}
\hline Factors & Treatments & Dp & Cn & Pt & Pn & Mv & MvAc & MvCm & TMA & TAE \\
\hline I & Nonirrigated & 8.91 & 7.70 & 12.14 & 11.06 & 141.34 & 18.92 & 18.38 & 181.15 & 37.30 \\
& Irrigated & 9.26 & 7.65 & 14.60 & 12.80 & 205.86 & 24.91 & 26.17 & 250.17 & 51.08 \\
Y & Non-sprayed & 8.98 & 7.63 & 12.78 & 11.84 & 176.40 & 21.49 & 20.11 & 217.62 & 41.60 \\
& Sprayed & 9.19 & 7.72 & 13.97 & 12.01 & 170.81 & 22.34 & 24.44 & 213.70 & 46.78 \\
$\mathrm{IXY}$ & & $\mathrm{ns}$ & $\mathrm{ns}$ & $\mathrm{ns}$ & $\mathrm{ns}$ & $\mathrm{ns}$ & $\mathrm{ns}$ & $\mathrm{ns}$ & $\mathrm{ns}$ & $\mathrm{ns}$ \\
\hline
\end{tabular}

Abbreviations: ns, not significant; Dp, delphinidin-3-O-glucoside; Cn, cyanidin-3-O-glucoside; Pt, petunidin-3-O-glucoside; Pn, peonidin-3-O-glucoside; Mv, malvidin-3-Oglucoside; MvAc, malvidin 3-O-acetate-glucoside; MvCm, malvidin 3-O-coumarate-glucoside; TMA, total monomeric anthocyanins in mg of malvidin-3-O-glucoside/g of skins; $\mathrm{TAE}$, total anthocyanin esters in $\mathrm{mg}$ of malvidin-3-O-glucoside/g of skins.

Irrigation and yeast application did not affect the parameters of wine phenolic composition (Table 7), with the exception of a significant irrigation $\times$ yeast application interaction for antioxidant activity. In fact, differences between yeast treatments for AA were observed only in nonirrigated vines (10.55 mM trolox /L for non-sprayed as compared to 7.44 $\mathrm{mM}$ trolox/L for sprayed vines), while no differences were observed between yeast application treatments under irrigated conditions (7.67 and $9.77 \mathrm{mM}$ trolox/L, respectively). However, when treatments were considered separately (Figure 7 ), wines produced from the combined IR/SP treatment had higher anthocyanin concentration $(288 \mathrm{mg} / \mathrm{L})$ and higher total phenol concentration (193 $\mathrm{mg}$ of gallic acid/L). There were no differences among treatments for C, TT, and OD280.

\section{Discussion}

Irrigation increased BW and SkW, without affecting SeW. It is generally reported that berry size is increased by irrigation, ${ }^{24}$ and according to Roby and Matthews, skin and seed mass per berry increase linearly with berry mass. ${ }^{25}$ Smaller berries are preferable for winemaking, because the skin-to-pulp ratio of small berries is higher than in larger ones, ${ }^{26}$ which is important as most of the important chemical compounds for winemaking are extracted from the skins. Regarding must composition, irrigation was found to accelerate pulp ripening as it was associated with higher sugar content and lower acidity of the grape must at harvest ${ }^{27}$ leading to wines with higher alcohol and lower TA. The higher must sugar levels of irrigated vines could be associated with an increased leaf assimilation rate and sugar translocation into the berries under more favorable water conditions. ${ }^{28}$

Irrigation increased anthocyanin and total phenol content (mg per berry) but had no impact on their concentration ( $\mathrm{mg} / \mathrm{g}$ of berry fresh weight). It seems as though the difference in anthocyanin content per berry could be the result of higher 


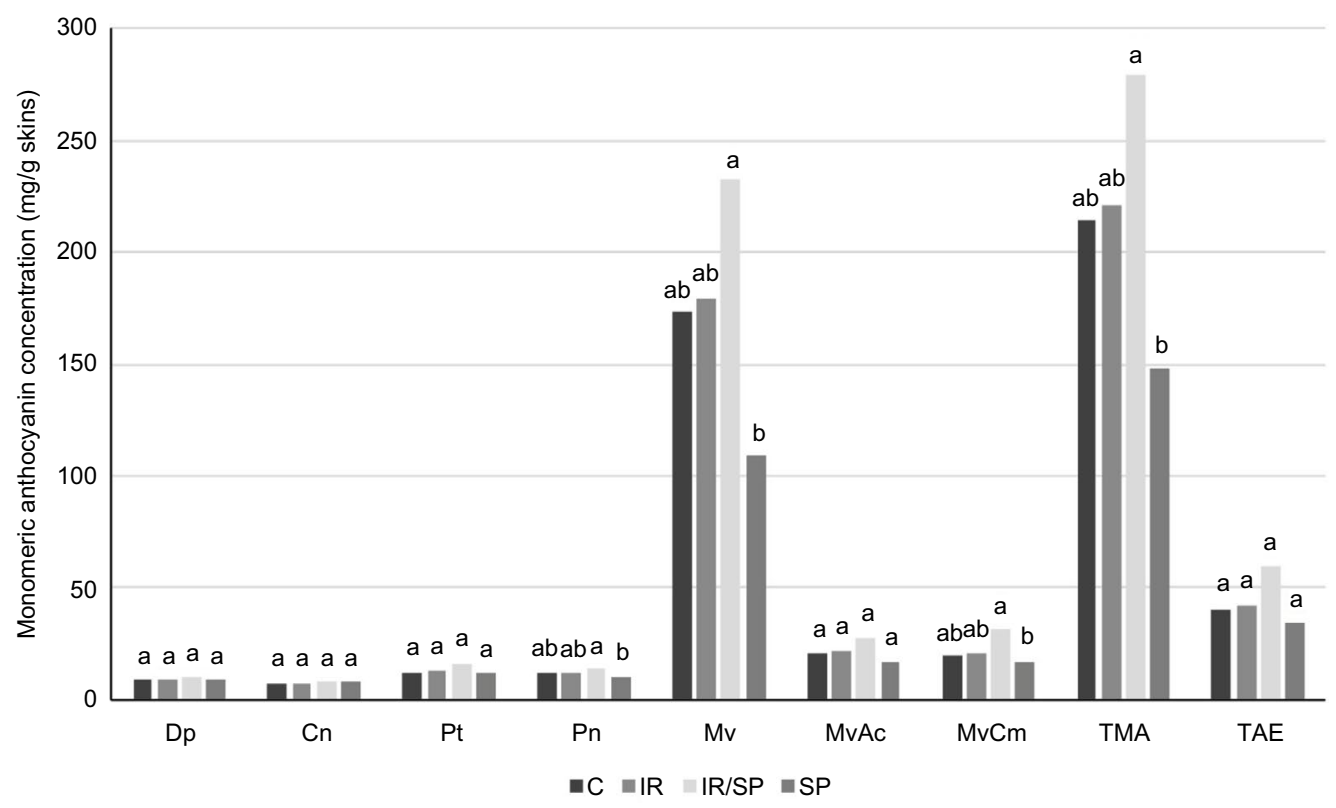

Figure 6 Anthocyanin concentration of the produced wines.

Notes: Different letters within a parameter denote significant differences (Duncan's test $p \leq 0.05$ ).

Abbreviations: Dp, delphinidin-3-O-glucoside; Cn, cyanidin-3-O-glucoside; Pt, petunidin-3-O-glucoside; Pn, peonidin-3-O-glucoside; Mv, malvidin-3-O-glucoside; MvAc, malvidin 3-O-acetate-glucoside; $\mathrm{MvCm}$, malvidin 3-O-coumarate-glucoside; TMA, total monomeric anthocyanins in mg of malvidin-3-O-glucoside/g of skins; TAE, total anthocyanin esters in mg of malvidin-3-O-glucoside/g of skins; C, control; IR, deficit irrigated; IR/SP, combined deficit irrigated and foliar sprayed; SP, foliar sprayed.

Table 7 Irrigation (I) and yeast application (Y) effects on phenolic composition of the produced wines

\begin{tabular}{llllllll}
\hline Factors & Treatments & Anth & TC & TT & TP & OD280 & AA \\
\hline I & Nonirrigated & 205 & 177 & 2.29 & 139 & 49.9 & 9.00 \\
& Irrigated & 266 & 177 & 2.36 & 180 & 52.0 & 8.73 \\
Y & Non-sprayed & 245 & 178 & 2.14 & 144 & 50.1 & 9.12 \\
& Sprayed & 226 & 176 & $2.5 \mathrm{I}$ & 175 & 51.7 & 8.61 \\
$\mathrm{I}$ & & ns & ns & ns & ns & ns & $* *$ \\
\hline
\end{tabular}

Notes: **Represents significance of the irrigation $\times$ yeast application $(\mathrm{I} \times \mathrm{Y})$ interaction at $p \leq 0.0 \mathrm{I}$.

Abbreviations: $\mathrm{ns}$, not significant; Anth, total anthocyanins in $\mathrm{mg} / \mathrm{L}$; TC, tannins in $\mathrm{mg}$ of catechin/L of wine; TT, total tannins in $\mathrm{g} / \mathrm{L}$ of wine; TP, total phenols in mg of gallic acid/L of wine; OD280, total polyphenol index; $A A$, antioxidant activity in $\mathrm{mM}$ trolox/L of wine.

SkW of the berries of irrigated vines compared to those from nonirrigated ones. Various authors reported an increase in skin anthocyanin levels under water deficit, ${ }^{29,30}$ while others have observed little or no effect under different conditions. ${ }^{31}$ Water deficit effects on berry phenolic compounds are often contrasting, depending on the period of water application and the severity of water restriction. ${ }^{32}$ Irrigation resulted in a lower tannin concentration in skins, confirming the results of Bucchetti et al, ${ }^{33}$ but tannin levels of the seeds remained unaffected. Wine phenolic composition was also not changed by irrigation.

Foliar application of yeast derivatives had no effect on $\mathrm{BW}$ and $\mathrm{SeW}$, in accordance with other authors who investigated this product, ${ }^{34,35}$ but it decreased skin mass, contrary to the findings of previous studies reporting a significant increase in berry skin thickness with foliar yeast applications. ${ }^{36}$ Application of yeast derivatives had no effect on must sugar concentration, $\mathrm{pH}$ or TA in accordance with Portu et al,${ }^{34}$ while Villangò et al reported variable effects of yeast derivative spray on grape $\mathrm{TA}$ and $\mathrm{pH}$ across different harvest dates and vintages. ${ }^{36}$

Foliar spraying had no effect on total anthocyanin and total phenol content per $\mathrm{g}$ of $\mathrm{BW}$, in accordance with previous studies under similar climatic conditions. ${ }^{34}$ Yeast application had no impact on individual anthocyanin composition of berry skins, with the exception of Dp, the levels of which were increased by yeast application. Portu et al presented similar results, but found increased Mv content instead of Dp. ${ }^{34}$ In contrast, Villangò et al observed, under cooler climate conditions, a positive or no significant effect of foliar yeast sprays on pigment accumulation across different harvest dates and experimental years, and they consistently found a higher anthocyanin extract- 


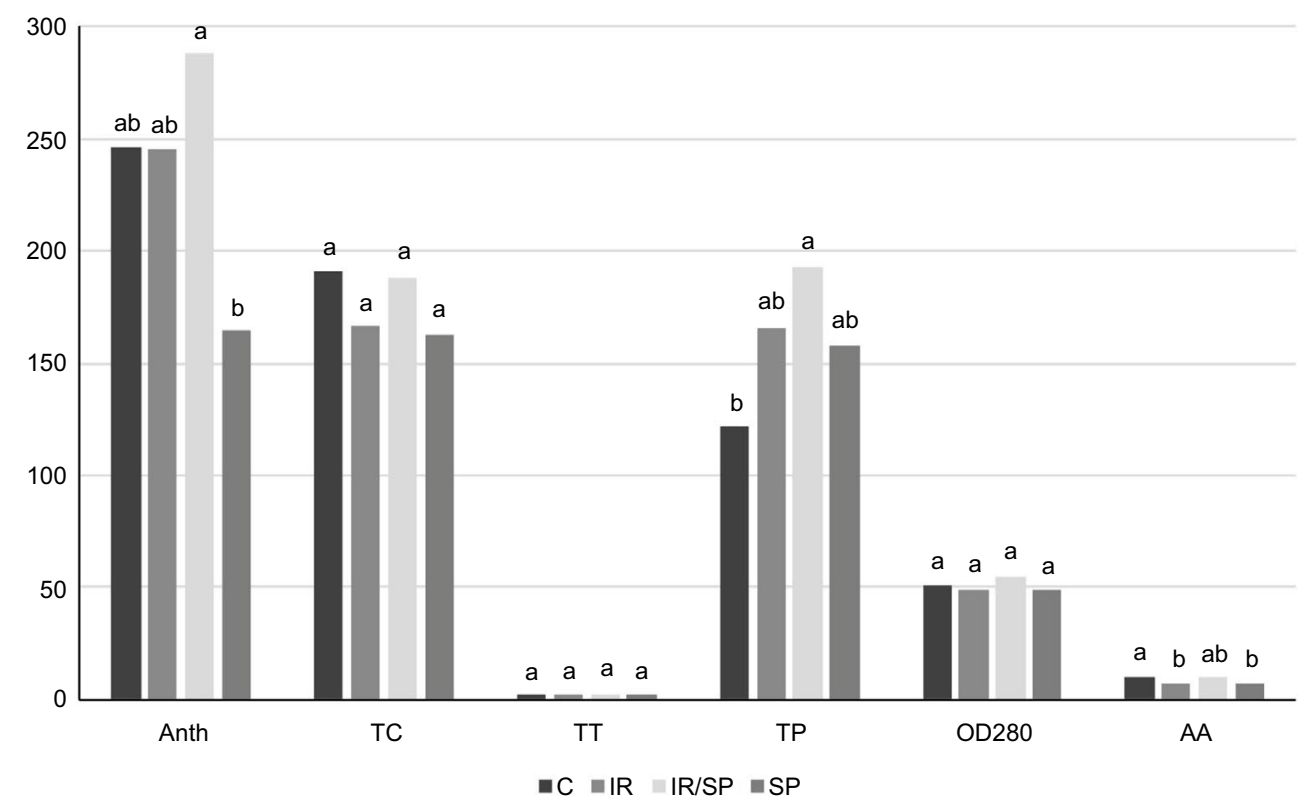

Figure 7 Phenolic composition of the produced wines.

Notes: Different letters within a parameter denote significant differences (Duncan's test $p \leq 0.05$ ).

Abbreviations: Anth, total anthocyanins in $\mathrm{mg} / \mathrm{L} ; \mathrm{TC}$, tannins in $\mathrm{mg}$ of catechin/L of wine; TT, total tannins in $\mathrm{g} / \mathrm{L}$ of wine; TP, total phenols in mg of gallic acid/L of wine; OD280, total polyphenol index; AA, antioxidant activity in $\mathrm{mM}$ trolox/L of wine; C, control; IR, deficit irrigated; IR/SP, combined deficit irrigated and foliar sprayed; SP, foliar sprayed.

ability in sprayed grapes. ${ }^{36}$ Differences between the latter work and our results could be related to the differences in climatic conditions and vine water relations between the two regions; it is possible that under the semiarid conditions of Greece, water conditions had a more marked influence on berry secondary metabolism, ${ }^{27}$ masking the effects of yeast derivative application. Moreover, the decreased phenolic content per berry under yeast application in the present study, is possibly related to the thinner skins of treated berries since anthocyanin and total phenol concentrations $(\mathrm{mg} / \mathrm{g} \mathrm{BW})$ were similar between sprayed and non-sprayed vines. ${ }^{34}$ Yeast application did not influence skin and seed tannin concentration, as also reported by Portu et al. ${ }^{34}$ Similarly, Villangò et al found no effect of foliar spray on seed maturity. ${ }^{36}$

Yeast application had no effect on alcohol concentration, TA or $\mathrm{pH}$ of the wines produced. The same result was reported by Portu et al in Tempranillo ${ }^{34}$ and Villangó et al in Syrah. ${ }^{36}$ There was also no impact on color intensity or color hue. ${ }^{34}$ In accordance with the results of grapes, foliar yeast spraying had no influence on anthocyanin composition of the wines. ${ }^{35}$ Portu et al reported similar findings ${ }^{34}$ (with the exception of Mv), ${ }^{34}$ while Villangó et al found no effect of yeast derivatives on wine anthocyanin concentration across different harvest dates and vintages, with the exception of one case per year, where anthocyanin concentration was higher in wines produced from treated vines. ${ }^{36}$ Yeast application did not affect wine total phenolics ${ }^{34,36}$ and tannin concentration. ${ }^{34}$ Lissarrague et al showed a significant increase in wine tannins caused by yeast application on Syrah grapes, ${ }^{35}$ while Villangó et al reported contrasting results among harvest dates and vintages regarding the concentration of monomeric catechins in wines from the foliar spray-treated grapes. ${ }^{36}$ However, in this study, wines produced form the combined IR/SP treatment had a higher anthocyanin concentration and higher total phenols.

\section{Conclusion}

In this work we investigated the effect of the application of yeast derivatives (LalVigne ${ }^{\circledR}$ Mature) on Agiorgitiko grape phenolic maturity and wine phenolic composition. According to our results, the application of yeast derivatives did not substantially modify the phenolic maturity of pulp, skins, and seeds, while it seemed to promote wine's phenolic potential only when associated with irrigation. Maybe a higher application rate or frequency of LalVigne ${ }^{\circledR}$ Mature is required to elicit the responses expected for Agiorgitiko grapes, in the semiarid climate of Southern Greece.

\section{Disclosure}

The authors report no conflicts of interest in this work. 


\section{References}

1. Intergovernmental Panel on Climate Change. Climate change 2014: synthesis report. IPCC; 2014. Available from: http://www.ipcc.ch/report/ ar5/syr/. Accessed March 1, 2017.

2. Jones GV, White MA, Cooper OR, Storchmann K. Climate change and global wine quality. Clim Change. 2005;73(3):319-343.

3. Anderson JD, Dimou P, Jones GV, et al. Harvest dates, climate, and viticultural region zoning in Greece. Proceedings of the $10^{\text {th }}$ International Terroir Congress; 7-10 July 2014, Tokaj, Hungary. 2014;2:55-60.

4. Tomasi D, Jones GV, Giust M, Lovat L, Gaiotti F. Grapevine phenology and climate change: relationships and trends in the Veneto region of Italy for 1964-2009. Am J Enol Vitic. 2011;62(3):329-339.

5. Salazar-Parra C, Aguirreolea J, Sánchez-Diaz M, Irigoyen JJ, Morales F. Effects of climate change scenarios on 'Tempranillo' grapevine (Vitis vinifera L.) ripening: response to a combination of elevated $\mathrm{CO}_{2}$ and temperature, and moderate drought. Plant and Soil. 2010;337(1):179-191.

6. Jones GV, Davis RE. Climate influences on grapevine phenology, grape composition, and wine production and quality for Bordeaux, France. Am J Enol Vitic. 2000;51:249-261.

7. Teixeira A, Eiras-Dias J, Castellarin SD, Gerós H. Berry phenolics of grapevine under challenging environments. Int J Mol Sci. 2013;14(9):18711-18739.

8. Koundouras S, Marinos V, Gkoulioti A, Kotseridis Y, van Leeuwen C. Influence of vineyard location and vine water status on fruit maturation of non-irrigated cv. Agiorgitiko (Vitis vinifera L.). Effects on wine phenolic and aroma components. J Agric Food Chem. 2006;54(14):5077-5086.

9. Castellarin SD, Matthiews MA, Di Gaspero G, Gambetta GA. Water deficits accelerate ripening and induce changes in gene expression regulating flavonoid biosynthesis in grape berries. Planta. 2007;227(1):101-112.

10. Castellarin SD, Pfeiffer A, Sivilotti P, Degan M, Peterlunger E, Di Gaspero G. Transcriptional regulation of anthocyanin biosynthesis in ripening fruits of grapevine under seasonal water deficit. Plant Cell Environ. 2007;30(11):1381-1399.

11. Koundouras S, Hatzidimitriou E, Karamolegkou M, et al. Irrigation and rootstock effects on the phenolic concentration and aroma potential of Vitis vinifera L. cv. cabernet sauvignon grapes. J Agric Food Chem. 2009;57(17):7805-7813.

12. Basile B, Marsal J, Mata M, Vallverdu X, Bellvert J, Girona J. Phenological sensitivity of 'Cabernet Sauvignon' to water stress: vine physiology and berry composition. Am J Enol Vitic. 2011;62:452-461.

13. Hardie WJ, Considine, JA. Response of grapes to water deficit stress in particular stages of development. Am J Enol Vitic. 1976;27:55-61.

14. Santamaría AR, Mulinacci N, Valletta A, Innocenti M, Pasqua G. Effects of elicitors on the production of resveratrol and viniferins in cell cultures of Vitis vinifera L. cv Italia. JAgric Food Chem. 2011;59(17):9094-9101.

15. Zhao J, Davis LC, Verpoorte R. Elicitor signal transduction leading to production of plant secondary metabolites. Biotechnol Adv. 2005;23(4):283-333.

16. Compendium of International Methods of Analysis of Wines and Musts (2 vol.). Available from: http://www.oiv.int/en/technical-standards-anddocuments/methods-of-analysis/compendium-of-international-methodsof-analysis-of-wines-and-musts-2-vol. Accessed August 6, 2013.

17. Iland P, Bruer N, Edwards G, Weeks S, Wilkes E. Chemical analysis of grapes and wine: techniques and concepts. Campbelltown, Australia: Patrick Iland Wine Promotions Pty Ltd; 2004.

18. Ribéreau-Gayon P, Glories Y, Maujean A, Dubourdieu D. Handbook of Enology. Chichester, UK: John Wiley \& sons Ltd; 1999.

19. Lorrain B, Chira K, Teissedre PL. Phenolic composition of Merlot and Cabernet-Sauvignon grapes from Bordeaux vineyard for the 2009-vintage: Comparison to 2006, 2007 and 2008 vintages. Food Chem. 2011;126(4):1991-1999.
20. Waterman PG, Mole S. Analysis of phenolic plant metabolites. In: Lawton JH, Likens GE, editors. Methods in Ecology. Oxford: Blackwell Scientific Publications; 1994;83-91.

21. Brand-Williams W, Cuvelier ME, Berset E. Use of a free radical method to evaluate antioxidant activity. LWT-Food Science Technology. 1994;28(1):25-30.

22. Harbertson JF, Picciotto EA, Adams DO. Measurement of polymeric pigments in grape berry extracts and wines using a protein precipitation assay combined with bisulfate bleaching. Am J Enol Vitic. 2003;54:301-306.

23. Kallithraka S, Mohdalya AA, Makris DP and Kefalas P. Determination of major anthocyanin pigments in Hellenic native grape varieties (Vitis vinifera sp.): association with antiradical activity. Journal of Food Composition and Analysis. 2005;18:375-386.

24. Bonada M, Jeffery DW, Petrie PR, Moran MA, Sadras VO. Impact of elevated temperature and water deficit on the chemical and sensory profiles of Barossa 'Shiraz' grapes and wines. Australian Journal of Grape and Wine Research. 2015;21(2):240-253.

25. Roby G, Matthews MA. Relative proportions of seed, skin and flesh, in ripe berries from 'Cabernet Sauvignon' grapevines grown in a vineyard either well irrigated or under water deficit. Australian Journal of Grape and Wine Research. 2004;10(1):74-82.

26. Casassa LF, Keller M, Harbertson JF. Regulated deficit irrigation alters anthocyanins, tannins and sensory properties of cabernet sauvignon grapes and wines. Molecules. 2015;20(5):7820-7844.

27. Kyraleou M, Koundouras S, Kallithraka S, Theodorou N, Proxenia N, Kotseridis Y. Effect of irrigation regime on anthocyanin content and antioxidant activity of Vitis vinifera L. cv. Syrah grapes under semiarid conditions. J Sci Food Agr. 2016;96(3):988-996.

28. Ollat N, Diakou-Verdin P, Carde JP, Bardieu F, Gaudillère JP, Moing A. Grape berry development: a review. Journal International des Sciences de la Vigne et du Vin. 2002;36(3):109-131.

29. Roby G, Harbertson JF, Adams DA, Matthews MA. Berry size and vine water deficits as factors in wine grape composition: anthocyanins and tannins. Australian Journal of Grape and Wine Research. 2004;10(2):100-107.

30. Esteban MA, Villanueva MJ, Lissarrague JR. Effect of irrigation on changes in the anthocyanin composition of the skin of cv. Tempranillo (Vitis Vinifera L.) grape berries during ripening. Journal of the Science of Food and Agriculture. 2001;81(4):409-420.

31. Koundouras S, Kanakis I, Drossou E, Kallithraka S, Kotseridis Y. Effects of post veraison water regime on the phenolic composition of grapes and wines of cv. Agiorgitiko (Vitis vinifera L.). Journal International des Sciences de la Vigne et du Vin. 2013;47(1):115-128.

32 Santesteban LG, Miranda C, Royo JB. Regulated deficit irrigation effects on growth, yield, grape quality and individual anthocyanin composition in Vitis vinifera L. cv. 'Tempranillo'. Agricultural Water Management. 2011;98(7):1171-1179.

33. Bucchetti B, Matthews MA, Falginella L, Peterlunger E, Castellarin SD. Effect of water deficit on Merlot grape tannins and anthocyanins across four seasons. Scientia Horticulturae. 2001;128:297-305.

34. Portu J, López R, Baroja E, Santamaría P, Garde-Cerdán T. Improvement of grape and wine phenolic content by foliar application to grapevine of three different elicitors: Methyl jasmonate, chitosan, and yeast extract. Food Chem. 2016;201:213-221.

35. Lissarrague JR, Téllez J, García E, Peiro E. Impact on agronomic parameters in vines and wine quality of foliar treatments with specific fractions of yeast derivatives. In: Proc 65th ASEV National Conference \& 39th ASEV Eastern Section Annual Meeting; July 23-27, 2014; Austin, Texas. Abstracts ASEV:121.

36. Villangó S, Pásti G, Kállay M, et al. Enhancing phenolic maturity of 'Syrah' with the application of a new foliar spray. South African Journal of Enology and Viticulture. 2015;36(3):304-315. 
International Journal of Wine Research

\section{Publish your work in this journal}

The International Journal of Wine Research is an international, peer-reviewed open-access journal that focuses on all scientific aspects of wine, including: vine growing; wine elaboration; human interaction with wine; health aspects of wine. The journal provides an open access platform for the reporting of evidence based studies on these topics. The manuscript management system is completely online and includes a very quick and fair peer-review system, which is all easy to use. Visit http://www.dovepress.com/testimonials.php to read real quotes from published authors.

Submit your manuscript here: https://www.dovepress.com/international-journal-of-wine-research-journal 